\title{
TURMA VIRTUAL PARA DISPOSITIVOS MÓVEIS NO SISTEMA INTEGRADO DE GESTÃO DE ATIVIDADES ACADÊMICAS
}

\author{
Gibeon Soares de Aquino Júnior, DIMAP, UFRN, gibeon@dimap.ufrn.br \\ Itamir de Morais Barroca Filho, IMD, UFRN, itamir.filho@imd.ufrn.br \\ Mário Andrade Vieira de Melo Neto, SINFO, UFRN, mario@info.ufrn.br \\ Taeko Elias Barbosa, SINFO, UFRN, taeko@info.ufrn.br
}

\begin{abstract}
Resumo. O advento da computação móvel, em particular a popularidade dos dispositivos móveis, vem modificando a maneira como os sistemas de informação são acessados e trazendo novas oportunidades de uso da computação em diversas áreas. Neste artigo relataremos o estudo de caso do desenvolvimento da aplicação do SIGAA para dispositivos móveis. Particularmente, focaremos no módulo de Turma Virtual, enfatizando a importância do mesmo para os docentes, discentes e para a própria instituição. Por fim, serão discutidos os resultados desta iniciativa, com base em dados e indicadores coletados a partir da instalação e uso do aplicativo.
\end{abstract}

Palavras-chaves: computação móvel, sistemas de informação, turma virtual.

\section{VIRTUAL CLASS FOR MOBILE DEVICES IN THE INTEGRATED SYSTEM FOR MANAGEMENT OF ACADEMIC ACTIVITIES}

\begin{abstract}
The advent of mobile computing, particularly the popularity of mobile devices, is changing the way how the information systems are used. Moreover, it is bringing new opportunities of computing use in several areas. In this paper, we report the case study of SIGAA mobile development. In particular, we emphasize the features of virtual class module. Finally, will be discussed the results of this initiative, based on data and indicators collected from application installations and its use.
\end{abstract}

Keywords: mobile computing, information systems, virtual class.

\section{Introdução}

A ascendência do uso de dispositivos móveis na sociedade atual vem criando um novo cenário na computação, alterando a expectativa e a maneira como os usuários interagem com os sistemas de informação existentes (Giessmann, 2012). Este novo cenário de uso da computação traz novas possibilidades, assim como restrições, as quais os usuários e desenvolvedores de software ainda estão se habituando (Kolici, 2013). Desta forma, um passo importante na área de desenvolvimento de software é repensar a maneira como os sistemas atuais precisam se adequar a essa nova forma de acesso.

Com base nesta motivação, a Universidade Federal do Rio Grande do Norte (UFRN) desenvolveu um aplicativo acadêmico para dispositivos móveis. O aplicativo se baseia nas funcionalidades do Sistema Integrado de Gestão de Atividades 
Acadêmicas (SIGAA), um sistema de informação web já existente, que informatiza diversos procedimentos da área acadêmica na UFRN. O objetivo principal deste aplicativo é prover novas formas de interação e acesso às informações inseridas por docentes e discentes no módulo de Turma Virtual do SIGAA.

Neste artigo relataremos a experiência do desenvolvimento do aplicativo do SIGAA para dispositivos móveis. Deste modo, a Seção 2 descreve o módulo de Turma Virtual, cujas funcionalidades foram escopo do aplicativo. Na Seção 3, é apresentada a abordagem usada para a adequação das funcionalidades da Turma Virtual para o contexto de dispositivos móveis. A implementação do aplicativo móvel e os resultados obtidos com a sua publicação no mercado de aplicativos são discutidos respectivamente nas seções 4 e 5. Por fim, na Seção 6, são apresentadas as considerações finais.

\section{O Módulo de Turma Virtual do SIGAA}

O SIGAA (Sistema Integrado de Gestão de Atividades Acadêmicas) é um sistema de informação web corporativo utilizado na UFRN e em diversas Universidades Federais que fazem parte da Rede de Cooperação IFES ${ }^{1}$. Ele é responsável por diversos procedimentos da área acadêmica, envolvendo graduação, pós-graduação (stricto e lato sensu), ensino técnico, ensino médio e infantil. Um dos módulos mais usados é a Turma Virtual, que é o espaço onde ocorre a interação entre o docente e o discente. $\mathrm{O}$ principal objetivo deste módulo é melhorar o processo de ensino-aprendizagem, criando uma extensão da sala de aula através de um ambiente virtual. A Figura 1 mostra a visão do docente ao acessar uma de suas turmas no semestre corrente. O docente possui total controle sobre as informações das disciplinas por ele ministradas, determinando inclusive quais as informações serão acessadas pelos discentes.

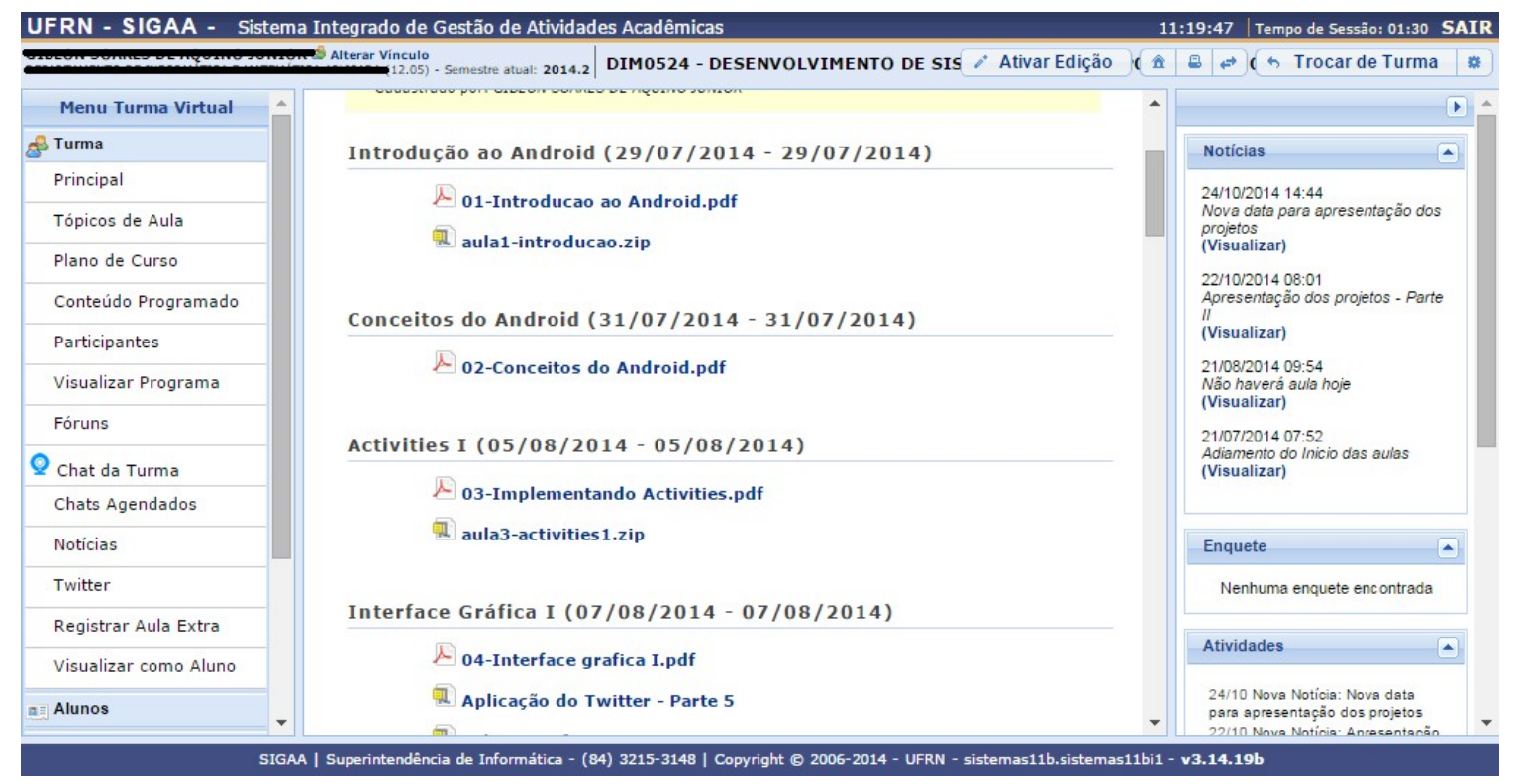

Figura 1 - Página principal da Turma Virtual (Visão Docente).

Entre as funcionalidades oferecidas a docentes e discentes podemos destacar:

\footnotetext{
${ }^{1}$ http://www.portalcooperacao.info.ufrn.br/
} 
- Plano de Curso: Permite ao docente informar a metodologia que será utilizada na disciplina, os procedimentos de avaliação da aprendizagem, horário de atendimento para encontros fora do horário de aula, cronogramas de aulas, avaliações e atividades.

- Fóruns: Local onde docentes e discentes podem criar os mais variados tópicos e discutir entre eles, aumentando assim a interação fora do contexto da sala de aula.

- Chat: A turma virtual possui a ferramenta de chat, que permite a comunicação através de texto escrito e vídeo. O chat funciona como uma sala de bate-papo tradicional, com a opção do docente transmitir áudio e vídeo em tempo real, e os discentes com a opção de fazerem comentário.

- Notícias: É possível ao docente cadastrar uma notícia de qualquer natureza que achar relevante e automaticamente todos os participantes da disciplina serão informados.

- Frequência e Notas: Os docentes podem lançar notas e frequências. Já os discentes podem acompanhar seu progresso na disciplina.

- Material Didático: O docente pode incluir qualquer material didático (Sites, Vídeos, Arquivos) que julgar necessário à disciplina e compartilhá-lo com todos os discentes matriculados na turma.

- Enquetes, Tarefas e Questionários: O docente poderá criar atividades para os discentes serem responderem e serem avaliados.

Esta ferramenta tem como missão aproximar docentes e discentes, sendo de suma importância para instituição, pois tende a melhorar o processo de ensino e aprendizagem, além de facilitar o processo de avaliação e acesso a informações das turmas. O SIGAA está em funcionamento desde 2006 e é usado por todos os discentes e docentes da instituição, além dos servidores técnicos administrativos que apoiam as atividades de ensino. Atualmente, o sistema é usado por 46.800 discentes, 4.490 docentes e 3.282 servidores técnicos administrativos somente na UFRN.

\begin{tabular}{|l|r|}
\hline Funcionalidade & Média de acessos diários \\
\hline Frequência dos Discentes & 3.504 \\
\hline Participantes das Turmas & 1.101 \\
\hline Material Didático & 1.066 \\
\hline Enquetes, Tarefas e Questionários & 931 \\
\hline
\end{tabular}

Tabela 1 - Média de acessos diários às principais funcionalidades da turma virtual

Foram coletados dados do período de 25/08/2013 a 12/11/2014 com o propósito de avaliar a quantidade de acessos às funcionalidades mais importantes da Turma Virtual, conforme pode ser visto na Tabela 1. Os dados coletados permitiram observar que o sistema possui uma média de 42.854 acessos diários. Somente a Turma Virtual possui uma média de 31.839 acessos diários. Estes números demonstram a importância do sistema para a instituição. 


\section{Adaptação da Turma Virtual para o contexto de dispositivos móveis}

Um dos motivos para a adoção massiva do sistema na UFRN e por outras instituições está no bom atendimento às necessidades de seus usuários, além da agilidade e compromisso da equipe de desenvolvimento em implementar, adaptar, evoluir e dar suporte ao mesmo. Outro fator que contribui para este sucesso é a adoção de tecnologias de ponta que permitam agilidade no desenvolvimento e possibilitem uma boa experiência dos usuários durante a interação com o sistema. Para manter este sucesso e continuar sendo apontado como referência é importante que o sistema acompanhe as mudanças tecnológicas atuais, em especial as demandas relacionadas ao novo cenário da computação móvel. Desta forma, é fundamental que o módulo de Turma Virtual seja repensado diante deste novo cenário tecnológico e que algumas funcionalidades sejam adaptadas para se adequarem à forma de interação de dispositivos móveis. Em alguns casos, é importante considerar que novas funcionalidades sejam implementadas para fazer uso de recursos tecnológicos disponíveis somente nestes tipos de dispositivos.

Neste sentido, diversos aspectos precisam ser considerados, já que o modo de uso de um dispositivo móvel é bem diferente de um computador desktop (Nosseir, 2012). Nestes são impostas restrições específicas, tais como, tamanho de tela, dificuldade de digitação de longos textos, capacidade de armazenamento e processamento, além de não haver garantia de acesso à rede (Nayebi, 2012). Da mesma maneira, novas oportunidades também são apresentadas, como mobilidade, localização, telas sensíveis à toque e gesto, além de diversas formas de conectividade.

Ao contrário do que se pensa, desenvolver uma aplicação móvel a partir de um sistema web já existente não é simplesmente converter as funcionalidades para uma nova plataforma (Barroca e Aquino, 2013a). É importante o uso de estratégias que levem em consideração os aspectos deste novo contexto, enquanto preserva a identidade do sistema web existente. Aquino e Barroca (2013) descrevem estratégias para adaptação de sistemas web já existentes para este novo contexto de dispositivos móveis. Particularmente, tais estratégias consideram três diferentes facetas, são elas: (a) Negócio, que envolve estratégias relacionadas ao escopo, envolvimento das partes interessadas e publicidade; (b) Aspectos técnicos, que envolve estratégias relacionadas ao código fonte do produto, como soluções arquiteturais, utilização de tecnologias, frameworks, padrões de projetos e boas práticas; (c) Interface gráfica, que envolve estratégias relacionadas à aparência visual e a forma como os usuários interagem com a aplicação móvel.

Em (Barroca e Aquino, 2013b) são descritos em detalhes como algumas estratégias foram implementadas durante o desenvolvimento do SIGAA Mobile. Uma das primeiras preocupações está relacionada ao escopo ou mais especificamente a escolha das funcionalidades e a forma como as mesmas precisam ser adaptadas para esse novo contexto. O SIGAA possui muitas funcionalidades e não faz sentido desenvolver todas estas funcionalidades para um dispositivo móvel. Por essa razão o escopo foi minimizado, levando em consideração somente as operações mais populares e convenientes para o contexto móvel. Nas primeiras versões procurou-se dar prioridade às funcionalidades relacionadas à interação entre docentes e discentes no processo de ensino e aprendizagem. Por este motivo, maior parte das operações implementadas é relativa à Turma Virtual. O envolvimento do usuário também é essencial para o sucesso 
da iniciativa (Beck e Andres, 2004; Majid et al, 2010). No desenvolvimento voltado para o contexto mobile essa prática se torna ainda mais importante. Com base nessa estratégia, vários docentes e discentes foram entrevistados antes de iniciar desenvolvimento. Tais entrevistas tiveram como propósito receber as expectativas e feedbacks sobre nossos planos.

Também levando em consideração a importância dos requisitos relacionados à interface gráfica e facilidade de interação do usuário, foi envolvida no projeto uma equipe específica para endereçar estes aspectos. A equipe de pesquisa e desenvolvimento da interface adotou a abordagem do Design Participativo - na qual os usuários (no caso do SIGAA, alunos e professores) foram envolvidos e participaram ativamente em todas as etapas do projeto (Muller, 1999; Santa Rosa e Moraes, 2012). Neste trabalho foram avaliados aspectos ergonômicos e de usabilidade e um conjunto de recomendações foram elaboradas à equipe de desenvolvimento (Santa Rosa et al, 2012).

\section{Turma Virtual no SIGAA Mobile}

O SIGAA Mobile foi desenvolvido para plataforma Android e finalmente foi publicado na Google Play em 25/04/2012. As funcionalidades contempladas pelo aplicativo consideram tanto os docentes quanto os discentes. Conforme pode ser visto na Figura 2, para o perfil de discente, ao acessar o menu principal, pode-se: consultar as suas turmas no período corrente; emitir documentos como histórico, atestado de matricula e declaração de vínculo; visualizar os horários e as notas do semestre; e ir para a versão web. O perfil do docente possui basicamente as mesmas opções, com exceção dos itens Notas e Documentos.
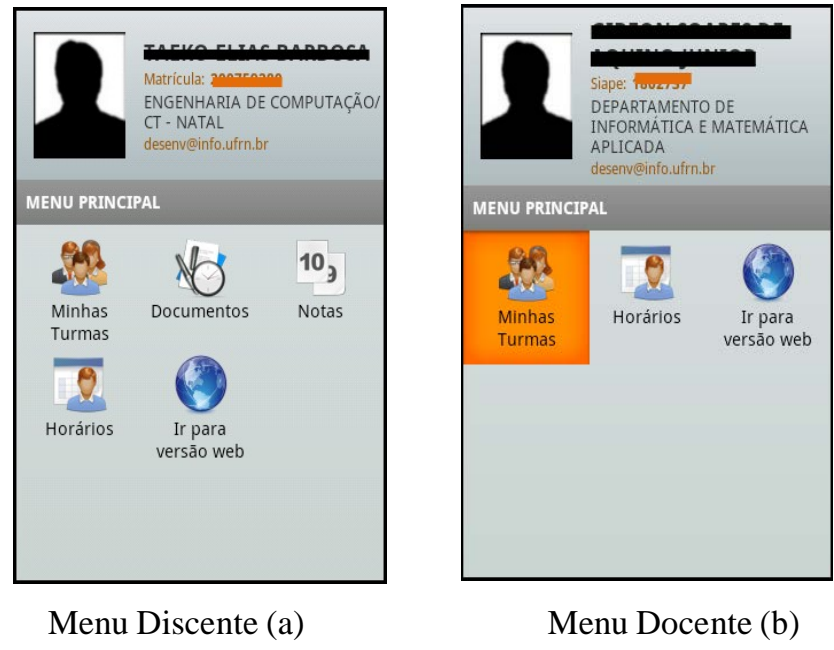

Figura 2 - Telas de Menu Principal do SIGAA Mobile

A partir do item de Minhas Turmas o discente pode acessar as turmas as quais está matriculado. Ao escolher uma turma, o aluno poderá ter informações sobre sua frequência, suas notas, as notícias disponibilizadas pelo professor, visualizar e contatar os demais participantes da turma e ter acesso aos tópicos de aulas, podendo, por exemplo, fazer download de arquivos enviados pelos professores. A Figura 3a apresenta estas opções.

A Figura 3b, demonstra o acesso no perfil docente. Basicamente, existem as mesmas opções, exceto a opção de Notas. Por outro lado, as opções disponíveis para o 
docente permitem o gerenciamento dos dados da turma, particularmente: Cadastro de Notícias (criar, remover e alterar), criação de Tópicos de Aula e o lançamento da Frequência.

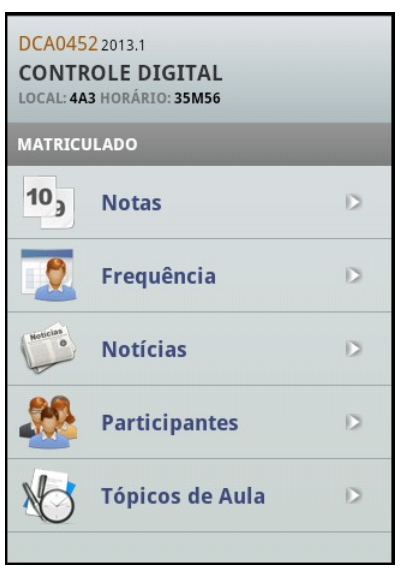

Discente (a)

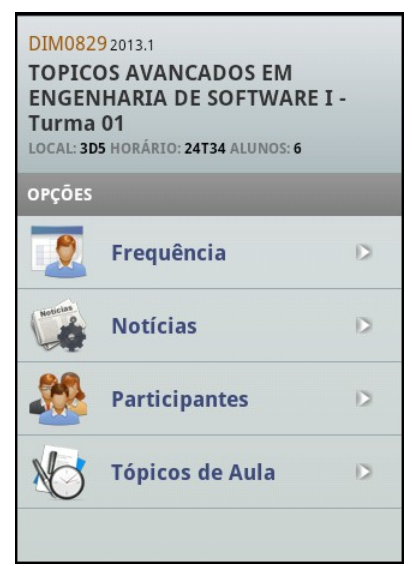

Docente (b)

Figura 3 - Telas de Turma Virtual do SIGAA Mobile

A opção Notas (disponível apenas para discentes) permite a visualização das notas lançadas pelo docente no SIGAA web em cada uma das unidades. Além disso, a opção de Frequência para os discentes, permite visualizar as presenças e faltas em cada dia de aula. Para docentes, este item permite que o usuário lance e altere frequências em cada um dos dias de aula. A Figura 4, apresenta as visões relativas à funcionalidade de Frequência para o docente (Figura 4a e Figura 4b) e para o discente (Figura 4c).

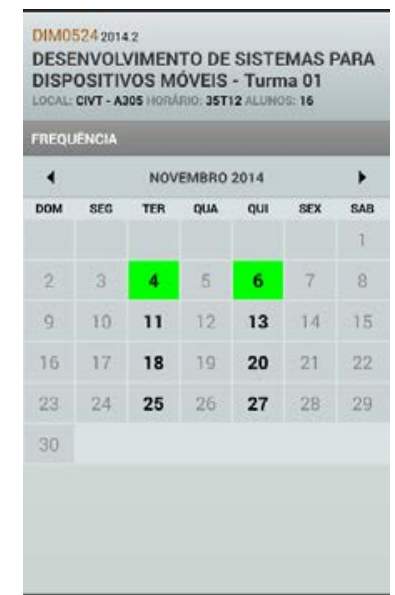

(a) Docente - Escolha da data

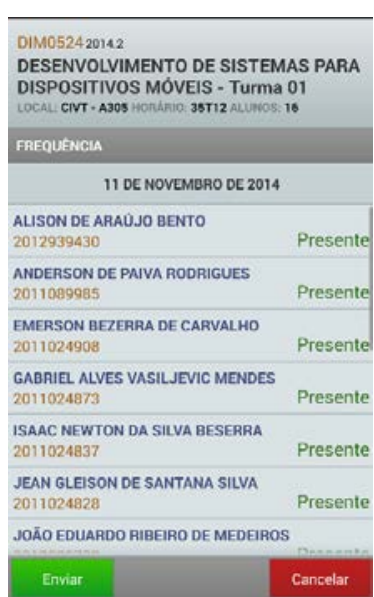

(b) Docente - Lançamento

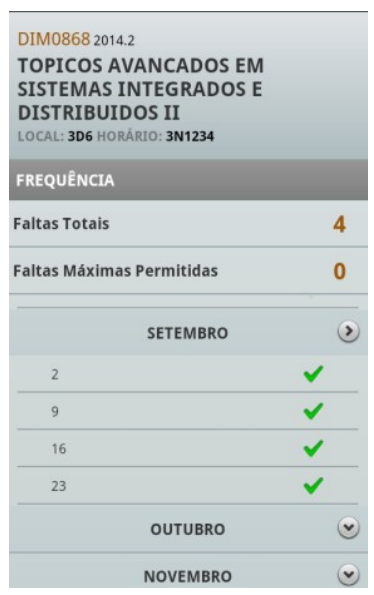

(c) Discente - Visualização

Figura 4 - Telas de Frequência para Discentes e Docentes

Na opção Notícias são listadas as notícias cadastradas pelo docente. As notícias são avisos importantes e informativos que dizem respeito à turma no decorrer do semestre. A única diferença entre os perfis de acesso, é que o docente pode criar, alterar ou remover notícias, conforme pode ser visto na Figura 5. 
A opção de Participantes permite aos discentes e docentes visualizar todos os integrantes da turma, mostrando foto, nome e email de cada um deles. Nas próximas versões, pretende-se adicionar opções que permitam a interação entre os participantes através de mensagens.
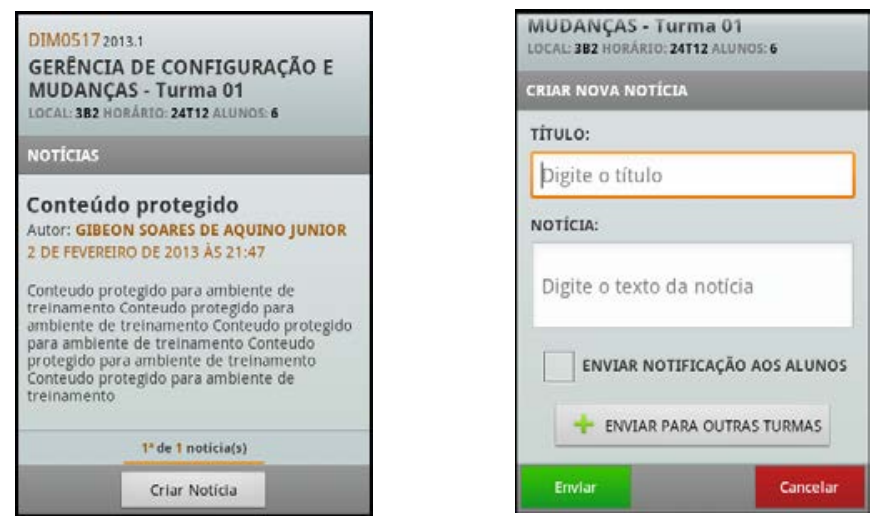

Figura 5 - Item Notícias para docente e formulário para criação de novas notícias

Por fim, o item Tópicos de Aulas, apresenta um cronograma de aula da turma e seus respectivos materiais (slides, documentos, links, vídeos e outros). A partir dessa funcionalidade é possível efetuar o download e abertura dos materiais. Para o perfil de docente, é possível criar novos tópicos de aulas e associar arquivos ao mesmo, conforme pode ser visto na Figura 6.
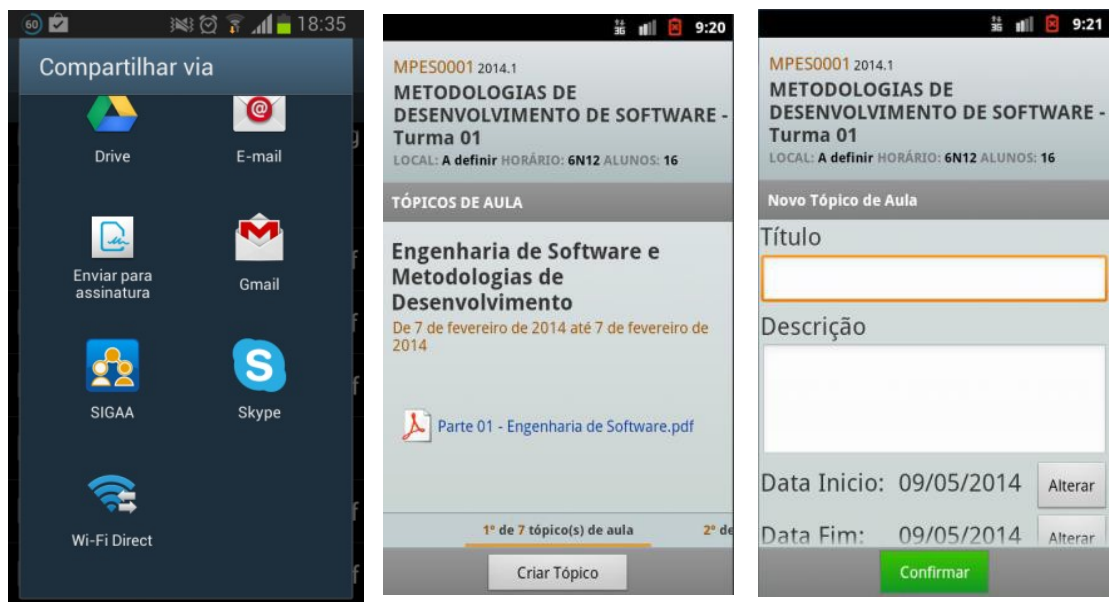

Figura 6 - Item Tópico de Aula para docente e compartilhamento de arquivo com o SIGAA mobile

A solução desenvolvida teve como base uma arquitetura baseada em camadas, conforme pode ser visto na Figura 7. A camada View contém todas as activities do aplicativo. Essas activities são componentes que interagem diretamente com a interface gráfica e manipulam os eventos do usuário. Estes, por sua vez, acessa, a camada denominada Bussiness Delegate que é responsável por delegar as requisições para a Cache Data Access, que é o repositório local de dados, ou para a Communication Channel, que representa a interface de comunicação com os serviços web. A escolha pelo componente que vai executar essas requisições é baseada na disponibilidade de conexão com a Internet. 


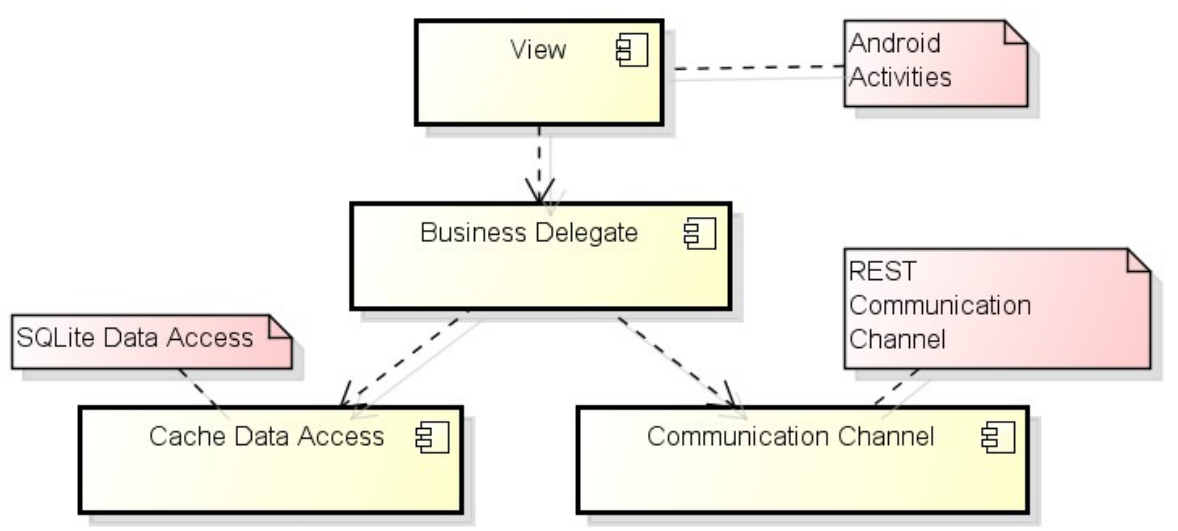

Figura 7 - Arquitetura de software do aplicativo SIGAA Mobile.

\section{Resultados}

Atualmente, o SIGAA Mobile está instalado em cerca de 9.000 dispositivos (instalações ativas) e com uma avaliação dos usuários de 4,25 (de um máximo de 5). O crescimento desde a sua disponibilização é apresentado na Figura 8.

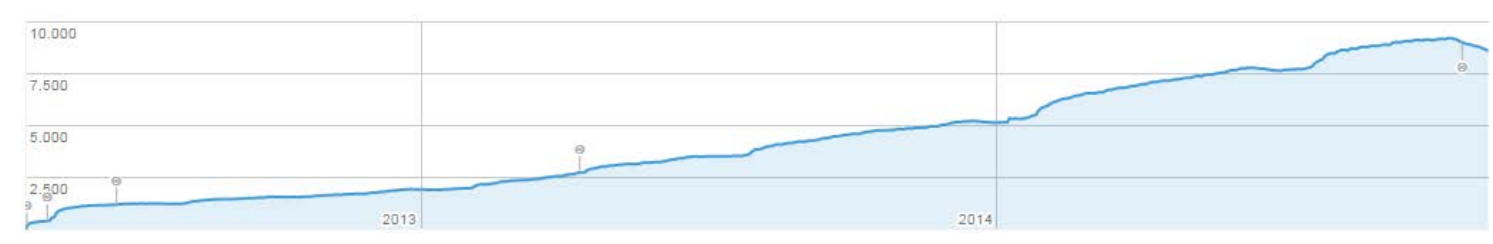

Figura 8 - Quantidade de instalações ativas do SIGAA Mobile.

Analisando os logins diários no aplicativo percebemos que esta aplicação tem uma média de aproximadamente 770 logins diários. Percebe-se um aumento nestes números no início e no final do período de atividades acadêmicas, tal como apresentado no gráfico da Figura 9. No mês de férias, o número de acesso diminui, mas imediatamente antes e imediatamente após este número cresce bastante.

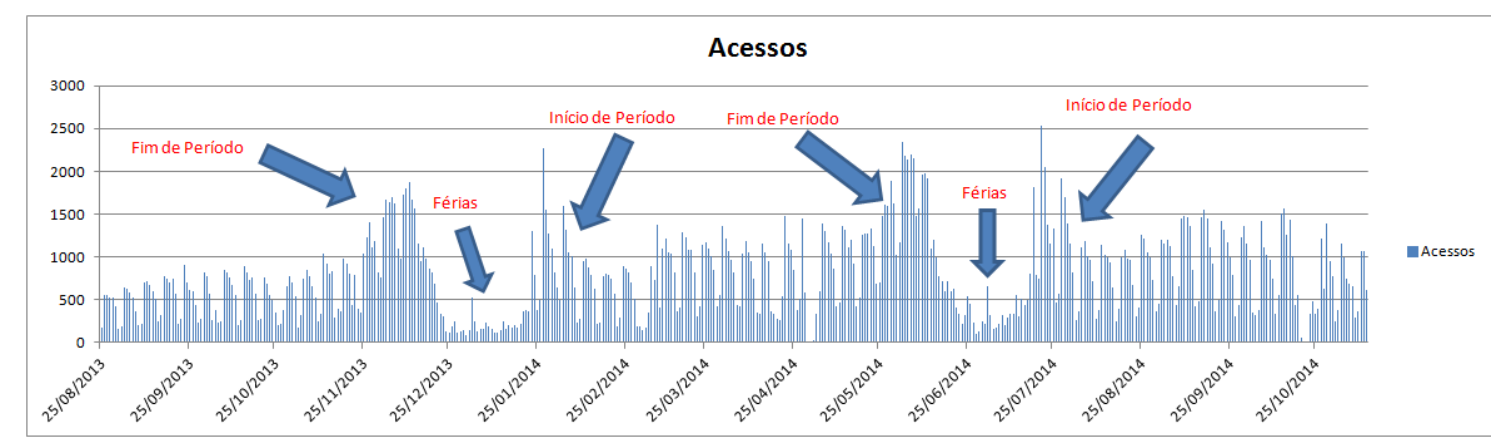

Figura 9 - Frequência de logins no SIGAA mobile.

A Tabela 2 apresenta os dados de acessos diários das funcionalidades mais usadas do aplicativo móvel. Os dados coletados também demonstram um bom uso da aplicação. Funcionalidades como Frequência e Notas do discente são as mais acessadas, tendo mais que 4.000 mil acessos por dia. 


\begin{tabular}{|l|c|}
\hline Funcionalidade & Média de Acessos Diários \\
\hline Frequência e Notas do discente & 4.780 \\
\hline Turmas do Discente & 2.379 \\
\hline Lista de participantes da turma & 1.266 \\
\hline Tópicos de Aulas da Turma & 468 \\
\hline Notícias da Turma & 345 \\
\hline
\end{tabular}

Tabela 2 - Média de acessos às funcionalidades da turma virtual no SIGAA Mobile.

\section{Considerações Finais}

Esse artigo apresentou a experiência do desenvolvimento das funcionalidades do SIGAA mobile. O mesmo apresenta uma versão para dispositivos móveis de um sistema de informação web já existente, com foco de desenvolvimento nas funcionalidades do módulo de Turma Virtual. Esse módulo é o espaço onde ocorre a interação entre o docente e o discente, tendo como principal objetivo melhorar o processo de ensinoaprendizagem através da criação de um ambiente virtual que tem como propósito ser uma extensão da sala de aula. Esse ambiente facilita a interação entre discente e docente, por meio de um aplicativo em um dispositivo móvel, fornecendo aos mesmos mecanismos para comunicação através de notícias, materiais e fóruns de dúvidas. Além disso, para a segunda versão desse aplicativo, planeja-se a criação de uma funcionalidade de chat (troca de mensagens instantâneas), onde discentes e docentes de uma turma poderão se comunicar instantaneamente. Essa funcionalidade também tem o objetivo de melhorar o processo de ensino-aprendizagem, uma vez que estreita ainda mais o laço entre os participantes de uma turma mesmo fora da sala de aula.

Baseado no entendimento que desenvolver uma aplicação móvel de um sistema web já existente não é simplesmente converter suas funcionalidades para uma nova plataforma foi usada a estratégia de pensar na aplicação móvel como algo novo, voltado para um dispositivo móvel. Neste processo, foram adotadas estratégias específicas, que levam em consideração os aspectos do contexto de dispositivos móveis, enquanto preserva a identidade do sistema web existente.

Os resultados apresentados demonstram que a estratégia adotada foi bem sucedida. O número de instalações ativas só vem crescendo ao longo dos anos e a avaliação média do aplicativo é bem alta. Os dados analisados também demonstram um bom uso da aplicação, funcionalidades como Frequência e Notas do discente são as mais acessadas. Tais estatísticas de uso do sistema são importantes indicadores das necessidades centrais dos usuários e permitem inferir comportamentos e demandas por informação. Além disso, tais informações são importantes para direcionar o esforço de desenvolvimento e aprimoramento de funcionalidades do sistema.

Por fim, como trabalhos de programação futuros, planejamos o desenvolvimento de novas funcionalidades para o SIGAA Mobile, tais como, recebimento de notificações de novidades (mensagens, publicações de notas e tarefas); recebimento de notificações de alertas/lembretes (datas de provas, prazo de trabalhos/tarefas e aproximação do limite 
de faltas) e comunicação em grupo (chat) possibilitando a interação entre os alunos e participantes; localização por GPS de setores, departamentos e salas de aula; e, principalmente, recursos que propiciem maior interação entre alunos e professores, de modo que o sistema possa oferecer contribuições para uma relação de ensinoaprendizagem centrada no aluno e de acordo com os preceitos da teoria de aprendizagem construtivista. Atualmente algumas dessas funcionalidades já estão sendo desenvolvidas.

\section{Referências}

Aquino, G. ; Barroca, I. Strategies about implementation of Mobile Applications from existing Web-based Enterprise Systems: a case study. In the 25th International Conference on Software Engineering and Knowledge Engineering, 2013. Boston, USA.

Barroca, I. ; Aquino, G. A metamorfose dos sistemas de informação na era da computação móvel. In Procedings of 2nd Simpósio Brasileiro de Tecnologia de Informação, 2013, Recife.

Barroca, I. ; Aquino, G. SIGAA Mobile - O caso de sucesso da ferramenta de gestão acadêmica na era da computação móvel. In: Simpósio Brasileiro de Informática na Educação, 2013, Campinas, São Paulo.

Beck, K.; Andres, C. Extreme Programming Explained: Embrace Change (2nd Edition). 2004. Addison-Wesley Professional.

Giessmann, A., Stanoevska-Slabeva K., Visser, B.: Mobile Enterprise Applications Current State and Future Directions. In: 45th Hawaii International Conference on System Science, pp. 1363\{1372. IEEE Press, Hawaii (2012)

Kolici, V., Xhafa, F., Pinedo, E., Nunez, J.: Analysis of Mobile and Web Applications in Small and Medium Size Enterprises. In: Eighth International Conference on P2P, Parallel, Grid, Cloud and Internet Computing. Compiegne (2013)

Majid, R.A.; Noor, N.L.M.; Adnan, W.A.W.; Mansor, S. (2010) A survey on user involvement in software Development Life Cycle from practitioner's perspectives. Computer Sciences and Convergence Information Technology (ICCIT), 2010 5th International Conference on, vol., no., pp.240,243, Nov. 30 2010-Dec. 22010.

Muller, M. et al. Participatory partices in the software lifeycle. In: Handbook of HumanComputer Interactions, 2ed. Amsterdam: Elservier Science B V. 1997.

Nayebi, F.; Desharnais, J.-M.; Abran, A. (2012) The state of the art of mobile application usability evaluation. Electrical \& Computer Engineering (CCECE), 25th IEEE Canadian Conference on , vol., no., pp.1,4, April 29 2012-May 22012.

Nosseir, A., Flood, D., Harrison, R., Ibrahim, O.: Mobile Development Process Spiral. In: 7th International Conference on Computer Engineering \& Systems. Cairo (2012)

Santa Rosa, J.G. \& Moraes, A. Design Participativo - técnicas para inclusão de usuários no processo de ergodesign de interfaces. Rio de Janeiro: Rio Books, 2012.

Santa Rosa, J.G., Gurgel, A. e Passos, M. Técnicas Baseadas em Etnografia e Prototipagem no Design de interface de Aplicativo Mobile para Gerenciamento Acadêmico. InfoDesign. São Paulo: v. 9 |n. 2 [2012], p. 88 - 99. 